University of Nebraska - Lincoln

DigitalCommons@University of Nebraska - Lincoln

Publications, Agencies and Staff of the U.S.

Department of Commerce

U.S. Department of Commerce

2006

\title{
Effect of deposition conditions on mechanical properties of low- temperature PECVD silicon nitride films
}

\author{
H. Huang \\ University of Queensland \\ K. J. Winchester \\ University of Western Australia \\ A. Suvorova \\ University of Western Australia \\ B. R. Lawn \\ National Institute of Standard and Technology, brian.lawn@nist.gov \\ Y. Liu \\ University of Western Australia \\ See next page for additional authors
}

Follow this and additional works at: https://digitalcommons.unl.edu/usdeptcommercepub

Part of the Environmental Sciences Commons

Huang, H.; Winchester, K. J.; Suvorova, A.; Lawn, B. R.; Liu, Y.; Hu, X. Z.; Dell, J. M.; and Faraone, L., "Effect of deposition conditions on mechanical properties of low-temperature PECVD silicon nitride films" (2006). Publications, Agencies and Staff of the U.S. Department of Commerce. 54.

https://digitalcommons.unl.edu/usdeptcommercepub/54

This Article is brought to you for free and open access by the U.S. Department of Commerce at DigitalCommons@University of Nebraska - Lincoln. It has been accepted for inclusion in Publications, Agencies and Staff of the U.S. Department of Commerce by an authorized administrator of DigitalCommons@University of Nebraska - Lincoln. 


\section{Authors}

H. Huang, K. J. Winchester, A. Suvorova, B. R. Lawn, Y. Liu, X. Z. Hu, J. M. Dell, and L. Faraone 


\title{
Effect of deposition conditions on mechanical properties of low-temperature PECVD silicon nitride films
}

\author{
H. Huang ${ }^{\mathrm{a}, *}$, K.J. Winchester ${ }^{\mathrm{b}}$, A. Suvorova ${ }^{\mathrm{c}}$, B.R. Lawn ${ }^{\mathrm{e}}$, Y. Liu ${ }^{\mathrm{d}}$, \\ X.Z. Hu ${ }^{\text {d }}$, J.M. Dell ${ }^{\text {b }}$ L. Faraone ${ }^{b}$ \\ a School of Engineering, The University of Queensland, Brisbane, Qld 4072, Australia \\ ${ }^{\mathrm{b}}$ School of Electrical, Electronic and Computer Engineering, The University of Western Australia, Perth, WA 6009, Australia \\ ${ }^{\mathrm{c}}$ Centre for Microscopy and Microanalysis, The University of Western Australia, Perth, WA 6009, Australia \\ ${ }^{\mathrm{d}}$ School of Mechanical Engineering, The University of Western Australia, Perth, WA 6009, Australia \\ e Materials Science and Engineering Laboratory, National Institute of Standard and Technology, Gaithersberg, MD 20899-8500, USA \\ Received 25 May 2006; received in revised form 7 July 2006; accepted 7 July 2006
}

\begin{abstract}
The effect of deposition conditions on characteristic mechanical properties - elastic modulus and hardness - of low-temperature PECVD silicon nitrides is investigated using nanoindentation. It is found that increase in substrate temperature, increase in plasma power and decrease in chamber gas pressure all result in increases in elastic modulus and hardness. Strong correlations between the mechanical properties and film density are demonstrated. The silicon nitride density in turn is shown to be related to the chemical composition of the films, particularly the silicon/nitrogen ratio.
\end{abstract}

(C) 2006 Elsevier B.V. All rights reserved.

Keywords: Elastic modulus; Hardness; PECVD; Silicon nitride; Thin film; Nanoindentation

\section{Introduction}

Silicon nitride thin films fabricated by plasma enhanced chemical vapor deposition (PECVD) have been widely used in semiconductor industry as passivation layers, diffusion barriers, gate dielectrics and isolation material [1,2]. More recently, the application of silicon nitride thin films has been extended to structural materials in micro-electro-mechanical systems (MEMS) devices, e.g., support structures for tunable mirrors in Fabry-Perot filters [3,4]. PECVD processes enable the deposition of silicon nitride thin films at much lower temperatures than those deposited by low-pressure chemical vapor deposition (LPCVD). Low-temperature deposition is of particular significance in the fabrication of MEMS devices that are temperature sensitive and relatively free of residual stresses.

While low-temperature deposition is a major advantage of the PECVD process, the silicon nitride thin films produced tend to be non-stoichiometric, i.e., $\mathrm{SiN}_{x}$ with $x \neq 4 / 3$ [5-7]. The actual

\footnotetext{
* Corresponding author. Tel.: +61 733653583 ; fax: +61 733654799.

E-mail address: han.huang@uq.edu.au (H. Huang).
}

composition of the films can be varied within certain range by adjusting the deposition conditions, including reactant gas mixing ratio and pressure, substrate temperature and plasma power [8-10]. The films may also contain hydrogen due to the gas chemistry used for deposition [11]. Mechanical properties are significantly influenced by the deposition conditions, and can be considerably different from those of their bulk material counterpart [12]. Mechanical characterization of thin films is therefore essential in gauging the potential structural integrity and performance in MEMS devices. In the past two decades, instrumented nanoindentation has attracted the attention of researchers as a simple, relatively non-invasive means of quantifying basic mechanical properties, specifically elastic modulus and hardness, of thin films on substrates [13-16]. Such an approach is especially well suited to determine the role of key deposition variables, such as substrate temperature, plasma power and chamber gas composition and pressure.

Accordingly, in this study an experimental investigation is

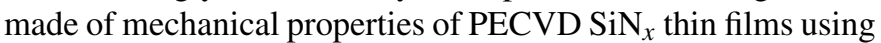
nanoindentation. Explicit relations are used to deconvolute the modulus and hardness of the films from measurements on asdeposited film/substrate bilayers. The modulus and hardness are 
found to correlate strongly with film density, which in turn correlates with ratio of silicon and nitrogen elements within the film. The effect of deposition conditions on the mechanical properties of thin films is discussed in terms of gas chemistry and deposition conditions.

\section{Experimental method}

\subsection{PECVD silicon nitride thin films}

$\mathrm{SiN}_{x}$ thin films were deposited onto $300 \mu \mathrm{m}$ thick (0 01 1) $\mathrm{Si}$ substrates using a PECVD system (PLASMALAB 80, Oxford Instruments, Oxford, UK). The process gases for PECVD were $\mathrm{SiH}_{4}, \mathrm{NH}_{3}$ and dilutant $\mathrm{N}_{2}$. Films were deposited at different substrate temperatures, radio frequency (RF) powers, and chamber gas pressures. Detailed PECVD conditions are listed in Table 1 .

The film surfaces were examined using atomic force microscopy (SPM D3000, Digital Instruments, Santa Barbara, USA), scanning electron microscope (Zeiss Supra 55VP, Carl Zeiss AG, Germany), and white light interferometer. The microstructure of the films was examined using cross-sectional transmission electron microscopy (TEM Jeol 3000F).

\subsection{Measurement of thin film density}

PECVD $\mathrm{SiN}_{x}$ film density was evaluated using a microbalance system. In this system, a quartz crystal was placed at the same level as the Si substrate in the PECVD chamber. The residual stress measurement and microstructural characterization of the films deposited under the same conditions but on different substrates indicated that the change of substrates was unlikely to cause any significant microstructural change in the films deposited, hence their material properties. As a result, the density values of the films grown on the quartz in our experiments can be well correlated to the real densities of those films grown on the Si substrate. Special care was also taken to make sure that the thin film was uniformly deposited on one side of the crystal, the silicon nitride deposition mass increment, $\Delta m$, was obtained by measuring the change of resonant frequency, $\Delta f$, of the crystal. The relationship between $\Delta m$ and $\Delta f$ is described by the Sauerbrey equation [17], i.e.,

$\Delta f=-\frac{2 f_{0}^{2} \Delta m}{\left(\rho^{1 / 2} \mu^{1 / 2} A\right)}$

where $f_{0}$ is the fundamental frequency, $\rho$ the density, $\mu$ the shear modulus and $A$ the actively resonating area of the crystal,

Table 1

PECVD conditions

\begin{tabular}{ll}
\hline Parameter & Value \\
\hline Gas flow ratio: $\mathrm{SiH}_{4} / \mathrm{NH}_{3} / \mathrm{N}_{2}$ & $1 / 10 / 20$ \\
Substrate temperature $\left({ }^{\circ} \mathrm{C}\right)$ & $125,150,200,300$ \\
Radio frequency $(\mathrm{RF})$, Power $(\mathrm{W})$ & $40,120,200$ \\
Chamber pressure $(\mathrm{mTorr})$ & 200,600 \\
Radio frequency $(\mathrm{MHz})$ & 13.6 \\
\hline
\end{tabular}

respectively. Knowing the thin film thickness, measured using a profilometer, the density was thus determined.

\subsection{Determination of Si:N ratio in thin films}

Energy dispersive X-ray spectroscopy (EDS) was used to characterize the silicon and nitrogen composition in the thin films. The EDS microanalysis was carried out using an Oxford Instruments EDS detector (Oxford Instruments, Oxford, UK) attached to the SEM. The EDS spectra were obtained using a primary beam energy of $5 \mathrm{keV}$, which provided sufficient nitrogen and silicon X-ray excitation and appropriate in-depth resolution. The penetration depth of the beam was maintained at less than half the film thickness to avoid substrate effects. The ratio of $\mathrm{Si}$ to $\mathrm{N}$ in the films was evaluated by comparing a bulk $\mathrm{Si}_{3} \mathrm{~N}_{4}$ standard (Tangaloy, Kawasaki, Japan) and using the ZAF correction procedure [18]. For each film, the EDS spectra were taken at three different spatial locations. The statistical error for the concentration determination was $\pm 5 \%$.

\subsection{Determination of elastic modulus and hardness of thin films}

Nanoindentation experiments were conducted using a Hysitron TriboScope (Hysitron, Minneapolis, MN) nanomechanical testing instrument. A Berkovich indenter with a tip radius of $100 \mathrm{~nm}$ was used. For each specimen, 25 indents were performed at loads ranging from 40 to $9000 \mu \mathrm{N}$. Repeated indentation tests were performed on different specimens, and means and standard deviation were calculated. AFM was used to confirm that the indents were well-formed over this penetration range, as shown in Fig. 1. Determinations of elastic modulus $E$ and hardness $H$ were made from the load-displacement curves [14] over indenter penetration depths ranging from 50 to $250 \mathrm{~nm}$.

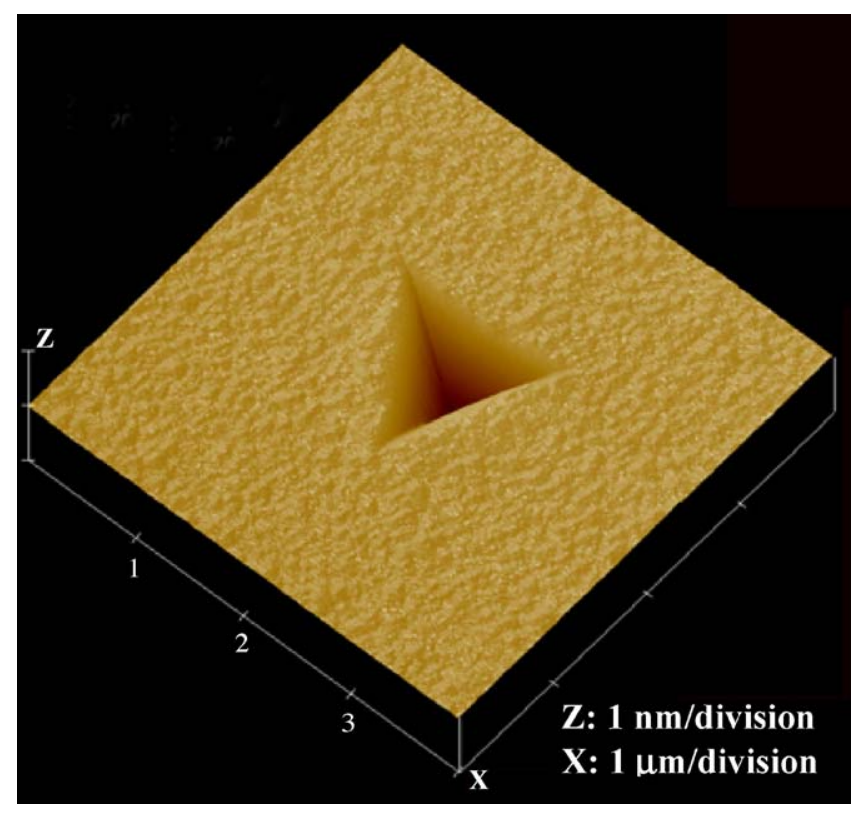

Fig. 1. AFM image of indent impressed using a load of $9 \mathrm{mN}$, showing well formed impression without pile-up along indent edges. 
For this purpose, a simple, empirical power-law relation was used to deconvolute $E$ and $H$ [16]:

$$
\begin{aligned}
& E=E_{\mathrm{s}}\left(\frac{E_{\mathrm{f}}}{E_{\mathrm{s}}}\right)^{L} \\
& H=H_{\mathrm{s}}\left(\frac{H_{\mathrm{f}}}{H_{\mathrm{s}}}\right)^{M}
\end{aligned}
$$

where subscripts f and s denote film and substrate and the indices $L$ and $M$ are dimensionless sigmoidal functions

$$
\begin{aligned}
& L=\frac{1}{\left[1+A(h / d)^{C}\right]} \\
& M=\frac{1}{\left[1+B(h / d)^{D}\right]}
\end{aligned}
$$

where $h$ and $d$ are the indentation contact depth and film thickness, respectively, and $A=3.76, B=1.47, C=1.38$ and $D=1.71$ are coefficients [16].

\section{Results}

\subsection{Surface characteristics and microstructure of thin films}

The SEM and AFM examinations of the film surface revealed that the films have "orange peel" characteristics. Fig. 2 shows an example viewed in the SEM. The surface features appeared equiaxial and their lateral scale ranged from 30 to $50 \mathrm{~nm}$. AFM imaging and white light interferometry indicated that the films have a surface roughness of $<5 \mathrm{~nm}$. No porosity was observed on the examined surfaces down to $5 \mathrm{~nm}$ resolution. TEM examinations indicated that the films studied were amorphous and homogeneous in atomic structure with depth, and defect-free. Fig. $3 \mathrm{a}$ and $\mathrm{b}$ are the TEM cross-sectional images of the film deposited at $125^{\circ} \mathrm{C}$, showing the microstructures near the film surface and the interface between the film and the Si substrate, respectively. No microstructural change was observed along the growth direction and the film appeared to be homogeneous. The diffraction pattern inserted in Fig. 3a indicated that the film was amorphous. Fig. 3c showed the microstructure of the

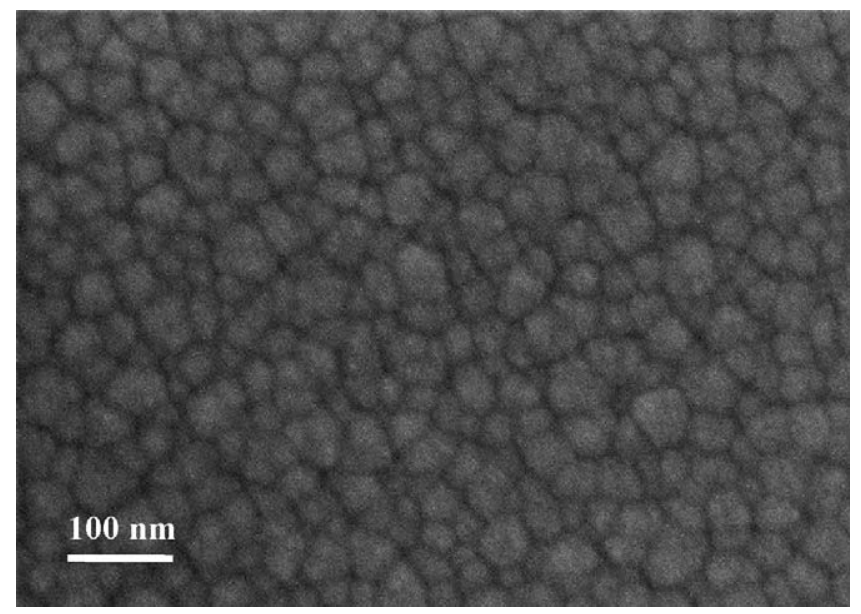

Fig. 2. SEM micrograph of PECVD silicon nitride deposited at $125^{\circ} \mathrm{C}$, showing surface "orange peel" structure.
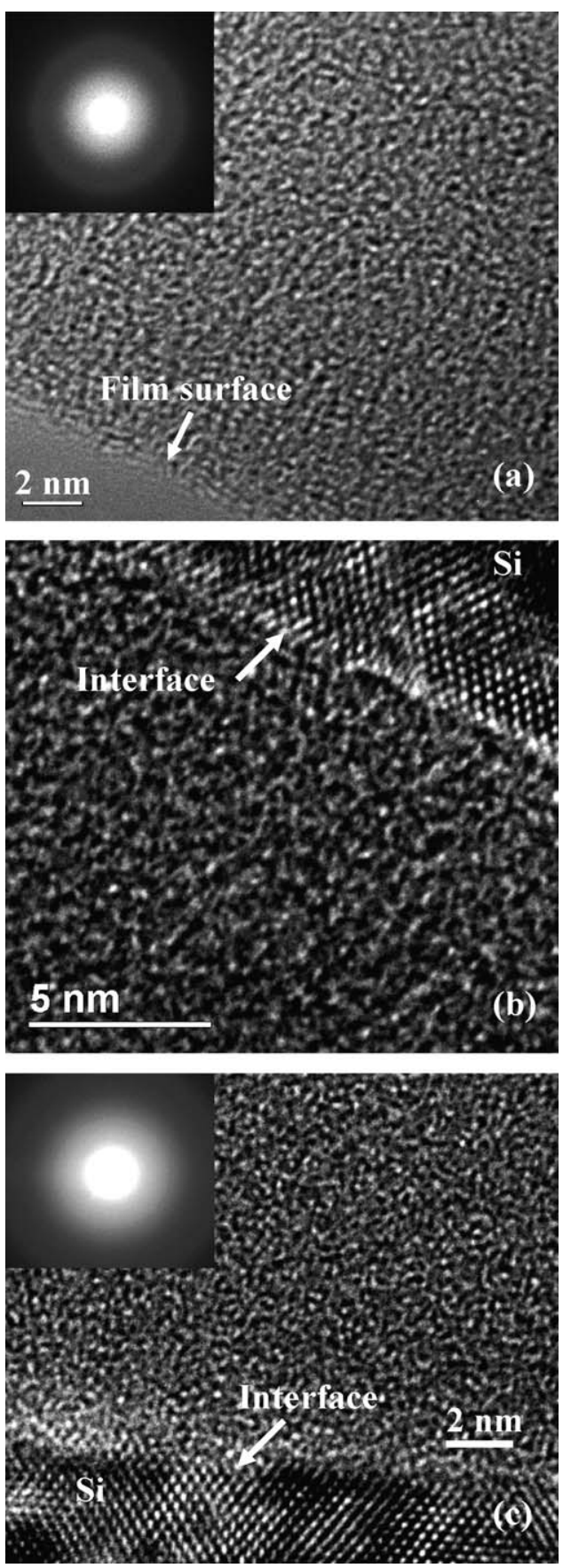

Fig. 3. (a) and (b) TEM micrographs of PECVD silicon nitride deposited at $125^{\circ} \mathrm{C}$, showing homogeneous structure along growing depth. (c) TEM micrograph of PECVD silicon nitride deposited at $300^{\circ} \mathrm{C}$. Inserted pictures are diffraction patterns of the films.

film deposited at the highest temperature of $300^{\circ} \mathrm{C}$, which was almost identical to that of the film deposited at $125^{\circ} \mathrm{C}$. The inserted diffraction pattern in Fig. 3c also indicated that this film had an amorphous structure.

\subsection{Nanoindentation data}

Values of $E$ and $H$ for the $\mathrm{SiN}_{x} / \mathrm{Si}$ bilayer systems are plotted as a function of the $h / d$ in Figs. 4-6 for different substrate temper- 


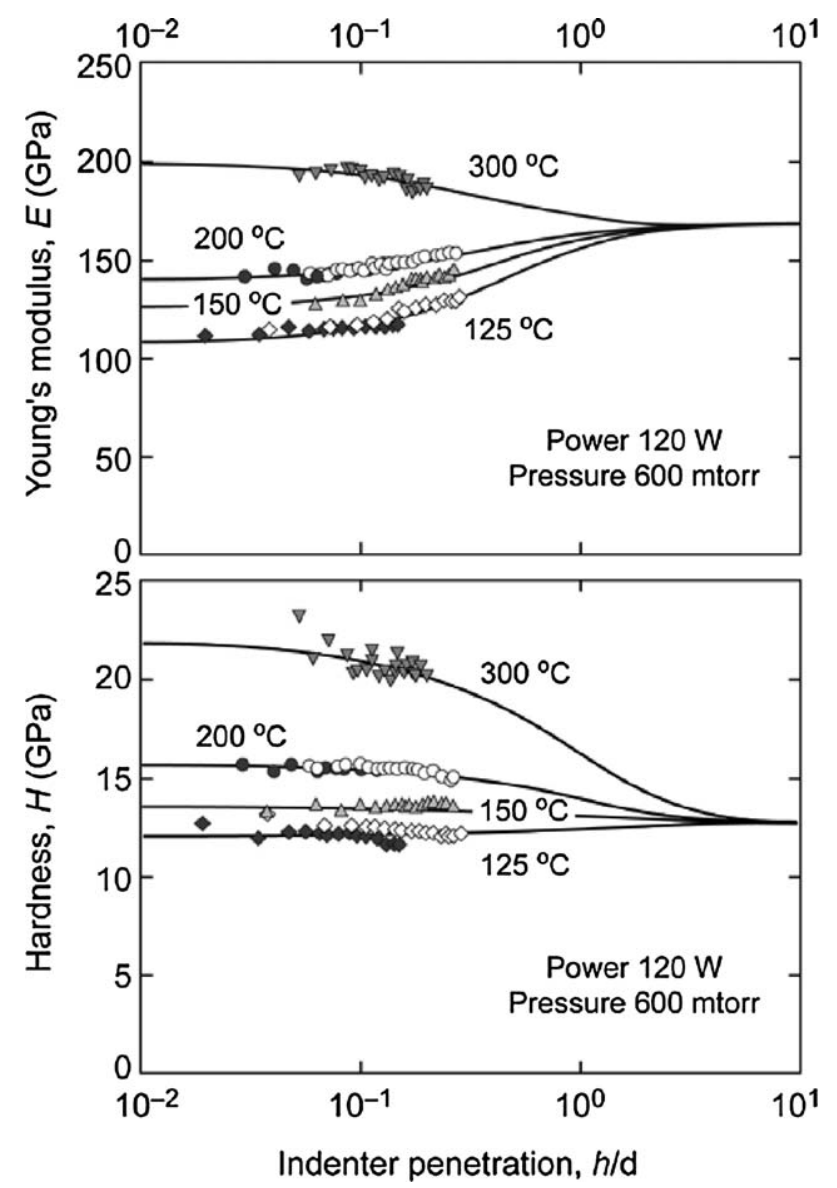

Fig. 4. Elastic modulus $E$ and hardness $H$ of PECVD silicon nitride films deposited at different substrate temperatures, plotted as a function of $h / d$. Fixed RF power and chamber pressure, film thicknesses are listed in Table 2. For the films deposited at 125 and $200^{\circ} \mathrm{C}$, open and solid legends are their data obtained from the thinner and thicker films, respectively. Data points are means. Solid curves are best fits according to Eqs. (1) and (2).

atures, RF powers and gas chamber pressures, respectively. Data points in these figures are means of a minimum of 5 indents at each test condition. Standard deviations (omitted from the plots to avoid excessive data overlap) are typically less than $5 \%$ of mean values. Solid curves are the best fits of Eqs. (1) and (2) to the average $E(h / d)$ and $H(h / d)$ data using $E=169.5 \mathrm{GPa}$ and $H=12.7 \mathrm{GPa}$ for $\left(\begin{array}{ll}1 & 0\end{array}\right)$ silicon [16]. For all the conditions used, these curves approach the Si limiting values asymptotically at

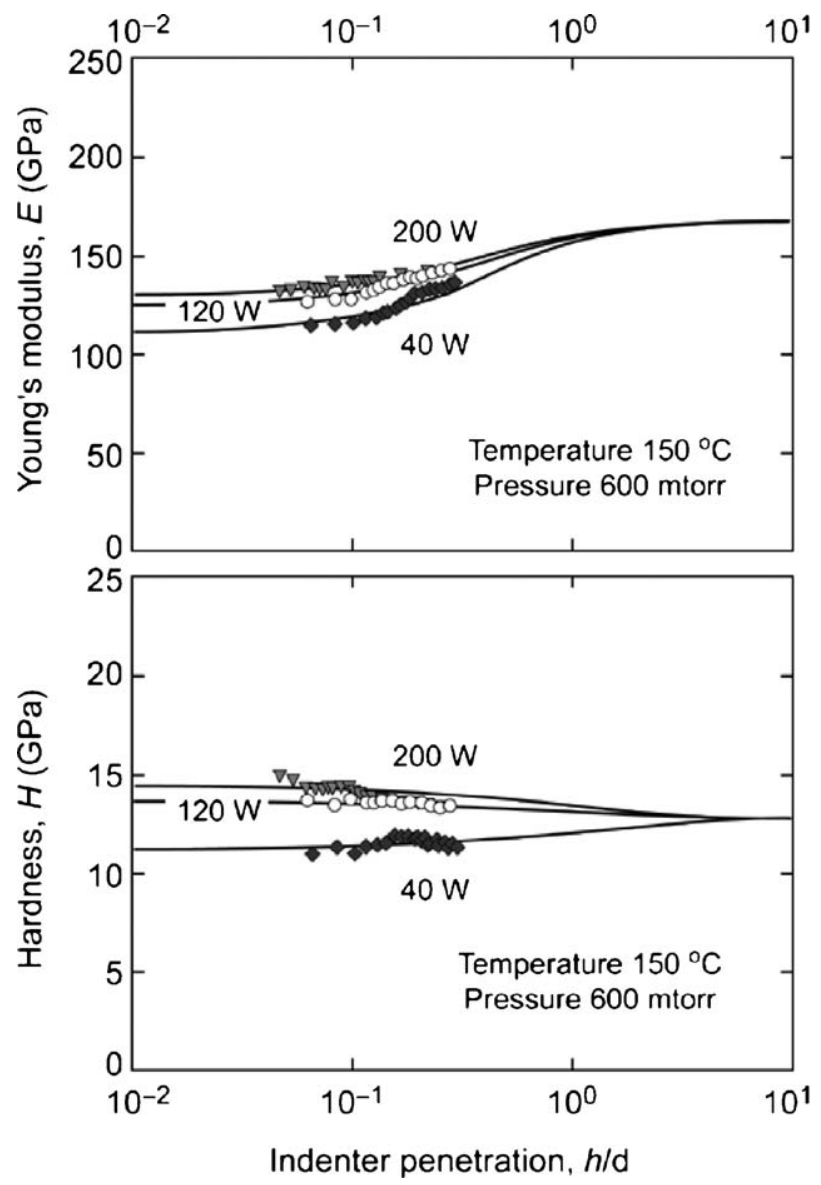

Fig. 5. Elastic modulus $E$ and hardness $H$ of PECVD silicon nitride films deposited at different RF powers, plotted as a function of $h / d$. Fixed temperature and chamber pressure, film thicknesses listed in Table 2. Data points are means. Solid curves are best fits according to Eqs. (1) and (2).

large $h / d$. Likewise, the asymptotic bounds of the curves at small $h / d$ represent $E$ or $H$ values for the thin films. Note that the $E$ and $H$ data fall on common curves for each set of deposition conditions, independent of film thickness $d$. The film properties under various deposition conditions produced by empirical fitting are summarized in Table 2.

Distinctive trends are evident from the nanoindentation data. Fig. 4 reveals substantial reductions in both $E$ and $H$ with decrease of substrate temperature from 300 to $125^{\circ} \mathrm{C}$, for fixed RF power and chamber pressure. Similarly, Fig. 5 reveals

Table 2

Mechanical properties of PECVD thin films under various deposition conditions

\begin{tabular}{llllll}
\hline $\begin{array}{l}\text { Substrate } \\
\text { temperature }\left({ }^{\circ} \mathrm{C}\right)\end{array}$ & RF power $(\mathrm{W})$ & $\begin{array}{l}\text { Chamber } \\
\text { pressure (mTorr) }\end{array}$ & Film thickness $(\mathrm{nm})$ & Density $\left(\mathrm{Mg} / \mathrm{m}^{3}\right)$ & Elastic modulus (GPa) \\
\hline 125 & 120 & 600 & 600,1195 & $2.2 \pm 0.2$ & $106.8 \pm 2.5$ \\
150 & 120 & 600 & 650 & $2.3 \pm 0.2$ & $124.8 \pm 2.5$ \\
200 & 120 & 600 & 605,1190 & $2.6 \pm 0.3$ & $140.2 \pm 3.4$ \\
300 & 120 & 600 & 585 & $2.8 \pm 0.3$ & $198.1 \pm 1.8$ \\
150 & 40 & 600 & 595 & $2.0 \pm 0.2$ & $110.6 \pm 2.2$ \\
150 & 200 & 600 & 1210 & $2.4 \pm 0.2$ & $130.3 \pm 2.1$ \\
150 & 120 & 200 & 715 & $2.5 \pm 0.3$ & $142.1 \pm 1.8$ \\
\hline
\end{tabular}



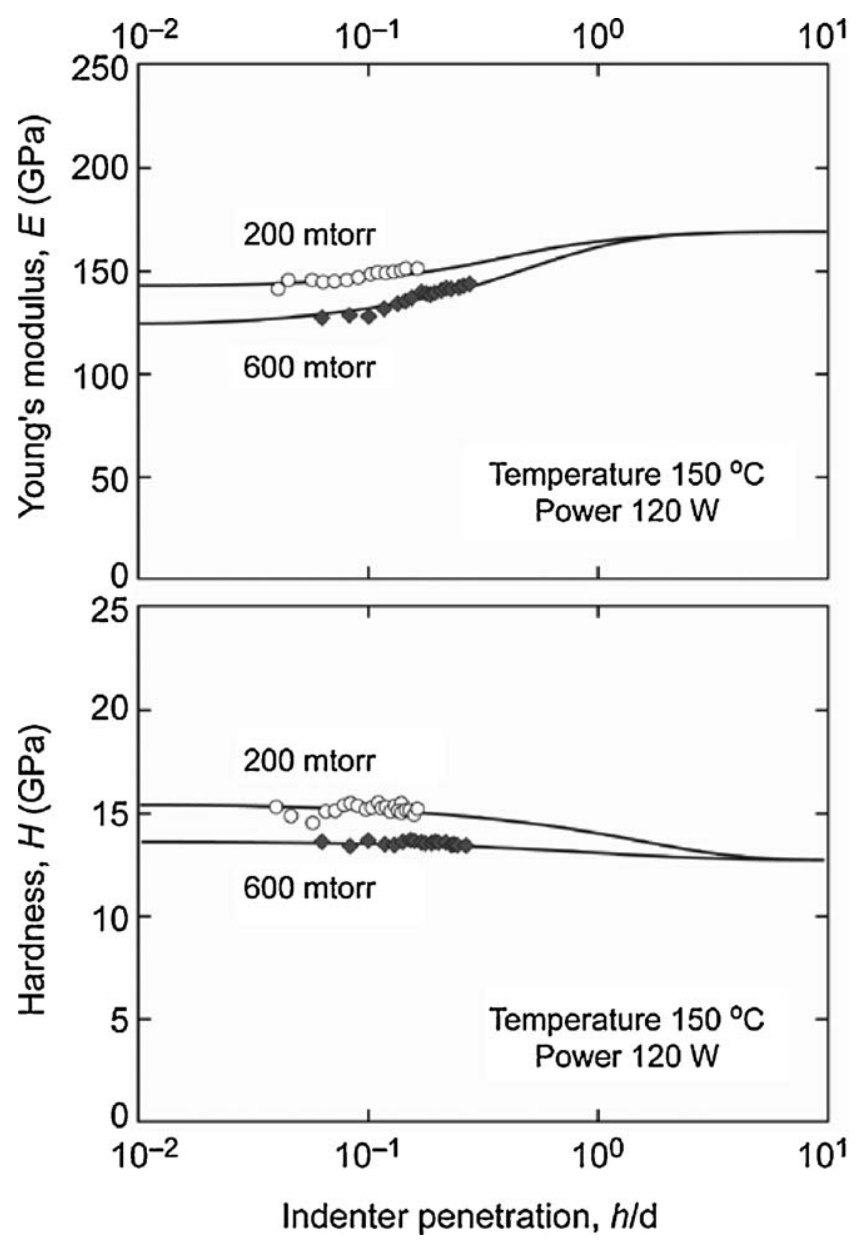

Fig. 6. Elastic modulus $E$ and hardness $H$ of PECVD silicon nitride films deposited at different chamber pressures, plotted as a function of $h / d$. Fixed RF power and substrate temperature film thicknesses listed in Table 2. Data points are means. Solid curves are best fits according to Eqs. (1) and (2).

decreases in $E$ and $H$ with decreasing RF power, for fixed substrate temperature and chamber pressure. Conversely, Fig. 6 shows an increase in $E$ and $H$ with decreasing chamber pressure, at fixed RF power and substrate temperature.

\subsection{Correlation of mechanical properties with density and composition stoichiometry}

Fig. 7 plots $E$ and $H$ obtained from the data fitting in Figs. 4-6 as a function of film density, values of which are included in Table 2. For comparison, singular data points (open symbols) are included for a much denser, LPCVD silicon nitride specimen deposited at a considerably higher temperature of $830^{\circ} \mathrm{C}$ [16]. (For this latter film a density $3 \mathrm{Mg} / \mathrm{m}^{3}$, equivalent to bulk stoichiometric silicon nitride, was assumed [19].) A correlation between mechanical properties and density is apparent.

To relate these results to film composition, Fig. 8 plots density as a function of Si:N ratio from the EDS measurements. Again, a comparison data point for LPCVD silicon nitride is included, assuming stoichiometric ratio. A near-linear dependence is evident in the data.
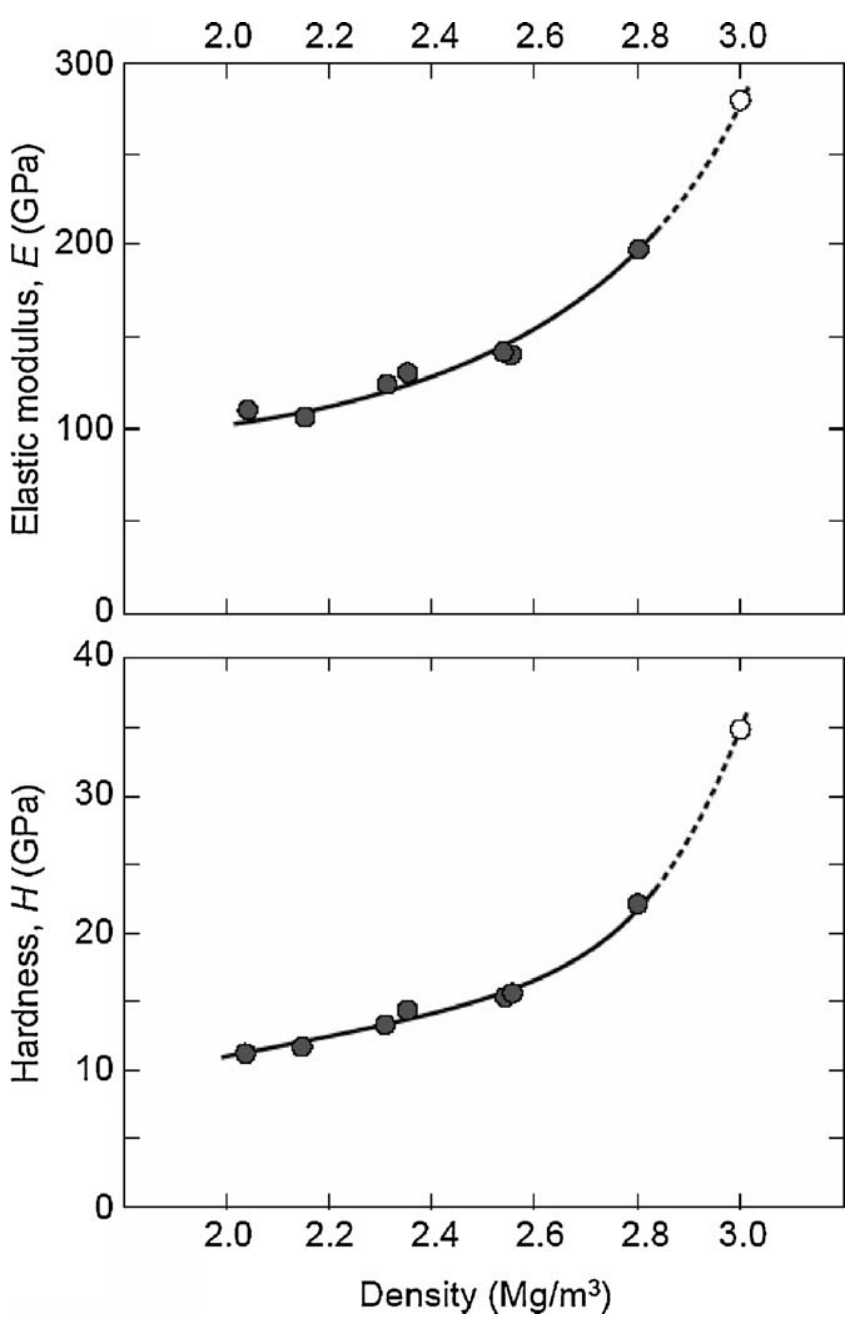

Fig. 7. Elastic modulus $E$ and hardness $H$ of PECVD silicon nitride films deposited under various conditions, plotted as a function of film density. Data represent best-fit values from Figs. 4-6, solid curve is empirical fit. Open symbol represents LPCVD silicon nitride.

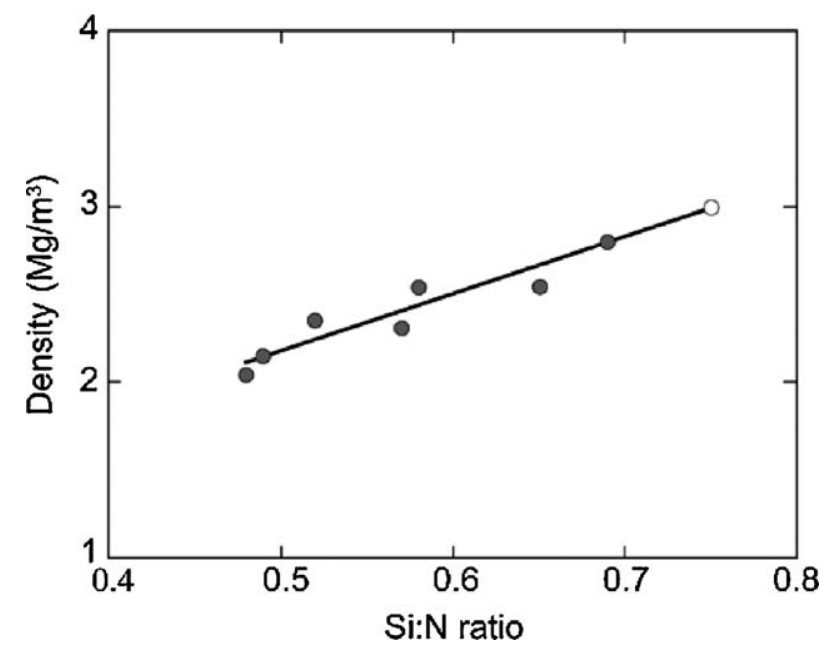

Fig. 8. Film density plotted as a function of ratio of silicon to nitrogen in PECVD silicon nitride films. Open symbol represents LPCVD silicon nitride. 


\section{Discussion}

In this paper, nanoindentation has been used to quantify the mechanical properties of PECVD silicon nitride thin films on silicon substrates. It is well documented that when using instrumented nanoindentation to determine elastic modulus and hardness, it may be necessary to allow for residual stresses [20,21]. In some cases these residual stresses can be substantial, and can superpose onto the indentation shear stresses driving the deformation process, thereby modifying the apparent property values $[22,23]$. However, the residual stresses in the low-temperature PECVD films studied here were relatively low, between $\pm 250 \mathrm{MPa}$ over the density range studied [24]. Such effects of stress are expected to be low as the measured maximum level of $250 \mathrm{MPa}$ [24] is less than $3 \%$ of the lowest hardness (Table 2). One manifestation of large residual stresses is an exaggerated material pileup around the indentation, a feature conspicuously absent in Fig. 1 [22,23].

Values for elastic modulus $E$ and hardness $H$ have been determined, making use of simple empirical formulae to deconvolute data for the film/substrate bilayers in Figs. 4-6. These figures are normalized along the indentation penetration coordinate $h$ so that data for films of different thicknesses $d$ fall onto a common curve for any given set of deposition conditions. The $E$ and $H$ curves tend asymptotically to values for silicon at large $h / d$ and for the film at small $h / d$. The results confirm that $E$ and $H$ for the PECVD silicon nitride films vary significantly with changes in substrate temperature, RF power and chamber pressure. Accordingly, nanoindentation presents itself as a simple and convenient probe technique for following variations in mechanical properties of thin films.

The variations in $E$ and $H$ with deposition conditions appear to correlate with changes in film density. These variations can be substantial, for instance up to a factor of $3 \mathrm{in} \mathrm{Fig.} \mathrm{7.} \mathrm{It} \mathrm{follows} \mathrm{that}$ nanoindentation can be used as a density probe, once basic data for any given PECVD silicon nitride system are obtained. This is a useful conclusion, because density determinations of thin films can be difficult and time consuming. The question then arises as to the origin of such density changes. Two possibilities are: (i) an increase in porosity, or (ii) a change in chemical composition. Our failure to detect any porosity from SEM and TEM examinations (Section 3.1) would appear to rule out the first of these hypotheses. On the other hand, the correlation between density and Si:N ratio in Fig. 8 leaves open the second hypothesis. The only issue that remains is the manner in which deposition conditions affect the chemical composition of the films, and thence the $\mathrm{Si}: \mathrm{N}$ stoichiometry.

To resolve this last issue, consider the chemistry of the silicon nitride film deposition. The synthesis in this study used a silane $\left(\mathrm{SiH}_{4}\right)$ and ammonia $\left(\mathrm{NH}_{3}\right)$ gas mixture as the source of $\mathrm{Si}$ and $\mathrm{N}$. Under the condition of 10:1 $\mathrm{NH}_{3}: \mathrm{SiH}_{4}$ ratio (Table 1), a twostage reaction [5] may occur

$$
\mathrm{SiH}_{4}+4 \mathrm{NH}_{3} \stackrel{\text { plasma }}{\longrightarrow} \mathrm{Si}\left(\mathrm{NH}_{2}\right)_{4}+4 \mathrm{H}_{2}
$$

$3 \mathrm{Si}\left(\mathrm{NH}_{2}\right)_{4} \stackrel{\text { heat }}{\longrightarrow} \mathrm{Si}_{3} \mathrm{~N}_{4}+8 \mathrm{NH}_{3}$ (while dilutant nitrogen was also present in the precursor gases, the deposition rate due to reaction between $\mathrm{SiH}_{4}$ and dissociated $\mathrm{N}_{2}$ for the PECVD conditions in the present experiments was negligible). With regard to Eq. (3a), RF power and chamber pressure are the main variables that affect aminosilane formation density and ion movement in the plasma, and subsequently influence aminosilane interaction with the film growth surface: higher RF power enhances aminosilane formation in the plasma; and in combination with lower chamber pressure, enhances ion bombardment on the substrate. The enhancement of ion bombardment in turn increases the packing density of the aminosilane on the substrate, leading to an increase in film density. Eq. (3b) implies the effect of substrate temperature on the stoichiometry of the silicon nitride formed. It is well known that stoichiometric $\mathrm{Si}_{3} \mathrm{~N}_{4}$ can be formed at high enough substrate temperature, but that this stoichiometry is compromised at the lower temperatures used here $[5,6]$. The lower-temperature films are also believed to contain a greater fraction of hydrogen, from incomplete dissociation of $\mathrm{Si}\left(\mathrm{NH}_{2}\right)_{4}$ in Eq. (3b), in which case it may be more appropriate to describe the product as $\mathrm{SiN}_{x} \mathrm{H}_{y}$ [5,6]. Under such conditions the $\mathrm{Si}: \mathrm{N}$ ratio would be expected to diminish, as evidenced by the EDS results in Fig. 8, reducing the film density still further.

\section{Concluding remarks}

The results shown in this paper clearly indicate that the elastic modulus, hardness, film density and chemical composition of low-temperature PECVD $\mathrm{SiN}_{x}$ films are significantly influenced by deposition conditions. Therefore, characterization of such properties is important for MEMS design and performance analysis. Modulus, hardness, film density and Si:N ratio are found to increase with increase in substrate temperature, and with increase in plasma power and decrease in chamber pressure. Strong correlations between the mechanical properties and the density of the films and between the density and the Si:N ratio are demonstrated.

The low temperature PECVD $\operatorname{SiN}_{x}$ would appear to be a viable structural material for MEMS fabrication. Even though film density does diminish with deposition temperature down to $125^{\circ} \mathrm{C}$, there is no indication of porosity or other potentially degrading microstructural defects. Perhaps most importantly, the basic mechanical properties of films for MEMS can be tailored to specification via judicious choice of deposition conditions.

\section{Acknowledgements}

The authors wish to thank Prof. M. B. Bush and Dr. M. Saunders from The University of Western Australia (UWA) for fruitful discussions. They would also like to acknowledge the sponsorship by the Australian Research Council (ARC) through discovery projects.

\section{References}

[1] M.D. Dange, J.Y. Lee, K. Sooriakumar, Microelectron. J. 22 (1991) 19. 
[2] T. Jana, S. Ray, Proc. SPIE, Proc. SPIE—Int. Soc. Opt. Eng. 3975 (2000) 845.

[3] K.J. Winchester, J.M. Dell, J. Micromech. Microeng. 11 (2001) 589.

[4] J.M. Dell, K.J. Winchester, C.A. Musca, J. Antoszewski, L. Faraone, IEEE Proceedings of the Conference on Optoelectron. \& Microelectron. Mat. \& Dev., (Sydney, Australia) December, 2002, pp. 567-570.

[5] D.L. Smith, A.S. Alimonda, J. von, P. Frederick, J. Vac. Sci. Technol. B8 (1990) 551.

[6] D.L. Smith, A.S. Alimonda, C.-C. Chen, S.E. Ready, B. Wacker, J. Electrochem. Soc. 137 (1990) 614.

[7] S. Sitbon, M.C. Hugon, B. Agius, F. Abel, J.L. Courant, M. Puech, J. Vac. Sci. Technol. A13 (1995) 2900.

[8] R. Vernhes, O. Zabeida, J.E. Klemberg-Sapieha, L. Martinu, Appl. Opt. 43 (2004) 97.

[9] E.P. Donovan, D. Van Vechten, A.D.F. Kahn, C.A. Carosella, G.K. Hubler, Appl. Opt. 28 (1989) 2940.

[10] P.L. Swart, P.V. Bulkin, B.M. Lacquet, J. Non-Cryst. Solids 187 (1995) 484.

[11] E. Bustarret, M. Bensouda, M.C. Habrard, J.C. Bruyere, S. Poulin, S.C. Gujrathi, Phys. Rev. B38 (1988) 8171.
[12] H. Huang, K.J. Winchester, Y. Liu, X.Z. Hu, C.A. Musca, J.M. Dell, L. Faraone, J. Micromech. Microeng. 15 (2005) 608.

[13] A.K. Bhattacharya, W.D. Nix, Int. J. Solids Struct. 24 (1988) 1287.

[14] W.C. Oliver, G.M. Pharr, J. Mater. Res. 19 (2004) 3.

[15] X.Z. Hu, B.R. Lawn, Thin Solids Films 322 (1998) 225.

[16] Y.-G. Jung, B.R. Lawn, M. Martyniuk, H. Huang, X.Z. Hu, J. Mater. Res. 19 (2004) 3076.

[17] G.Z. Sauerbrey, Z. Phys. 155 (1959) 206.

[18] K.F.J. Heinrich, Electron Beam X-ray Microanalysis, Van Nostrand, New York, 1981.

[19] S.D. Senturia, Microsystems Design, Kluwer Academic Publishers, 2000.

[20] T.Y. Tsui, W.C. Oliver, G.M. Pharr, J. Mater. Res. 11 (1996) 752.

[21] A. Bolshakov, W.C. Oliver, G.M. Pharr, J. Mater. Res. 11 (1996) 760.

[22] G. Sines, R. Carlson, ASTM Bull. 180 (1952) 35.

[23] T.R. Smies, S.G. Mellor, D.A. Hills, J. Strain Anal. 19 (1984) 135.

[24] M. Martyniuk, J. Antoszewski, C.A. Musca, J.M. Dell, L. Faraone, SPIE Proc. 5276 (2004) 451. 